University for Business and Technology in Kosovo

UBT Knowledge Center

UBT International Conference

2014 UBT International Conference

Nov 7th, 2:00 PM - 2:15 PM

\title{
On the role of GIS technology in Geospatial Education (QGIS vs ARGIS)
}

Shkelqim Kuka

Polytechnic University of Tirana, sh.kuka@fimif.edu.al

Jozef Bushati

University of Shkodra, jozefbushati@gmail.com

Follow this and additional works at: https://knowledgecenter.ubt-uni.net/conference

Part of the Computer Sciences Commons

\section{Recommended Citation}

Kuka, Shkelqim and Bushati, Jozef, "On the role of GIS technology in Geospatial Education (QGIS vs ARGIS)" (2014). UBT International Conference. 64.

https://knowledgecenter.ubt-uni.net/conference/2014/all-events/64

This Event is brought to you for free and open access by the Publication and Journals at UBT Knowledge Center. It has been accepted for inclusion in UBT International Conference by an authorized administrator of UBT Knowledge Center. For more information, please contact knowledge.center@ubt-uni.net. 


\title{
On the role of GIS technology in Geospatial Education (QGIS vs ARGIS)
}

\author{
Shkelqim Kuka ${ }^{1}$, Jozef Bushati ${ }^{2}$ \\ ${ }^{1}$ Polytechnic University of Tirana,Albania \\ ${ }^{2}$ University of Shkodra "Luigj Gurakuqi", \\ sh.kuka@fimif.edu.al ${ }^{1}$, jozefbushati@gmail.com ${ }^{2}$
}

\begin{abstract}
In the teaching of modeling concepts and spatial analysis, a major role play technologies and software. Anyhow main aim at the education is the teaching of concept independently on what kind of technologies and software will be used. The latter might be grouped in two categories: the commercial software and Open Source software. In this article emphasises the role of GIS technologies at the process of teaching and it is fulfilled an analysis advantages adn disadvantages between both software: commercial software ArcGis, and so called "Open Source" QuantumGis. Taking in to consideration the financial possibility of the educational institutions and also the complexity of its functionalities, it suggests that Qgis might be an acceptable alternative at the process of teaching and the practice at GIS lab.
\end{abstract}

Keywords: education, software, open source, ArcGis, Qgis

\section{Introduction}

A geographic information system, or GIS, is a computerized data management system used to capture, store, manage, retrieve, analyze, and display spatial information. Spatial analysis or spatial statistics includes any of the formal techniques which study entities using their topological, geometric, or geographic properties. Spatial statistics extends traditional statistics to support the analysis of geographic data. It provides techniques to describe the distribution of data in the geographic space (descriptive spatial statistics), analyze the spatial patterns of the data (spatial pattern analysis), identify and measure spatial relationships (spatial regression), and create a surface from sampled data (spatial interpolation, usually categorized as geostatistics) (Michael J de Smith et al, (2007) At the teaching curriculas of engineering faculties more and more are introduced courses where to are developed the concepts of geographics information systems, the geospatial analysis. Although main aim at the education is the teaching of concepts, the role of technologies and software in their demonstrations is big. For a discussion of the differences between education and training in GIS we reffer to: (Moore, John W.,(1998), (Longley et al (2011).

\subsection{The scope}

The study and implementation of any techniques of analysis and spatial modeling via GIS technologies has been too the aim of a teaching module that is going to be developed since years. Students will therefore be able to apply GIS-modeling concepts to real-world problems. During the implementation of knowledges at the labs there are exploited two software packets:

- QuantumGis and

- ArcGis Desktop

GIS software packages provide a unified approach to working with geographic information.

GIS software is constructed to provide a controlled environment for geographic information collection, management, analysis, and interpretation. The unified architecture and consistent approach to 
representing and working with geographic information in a GIS software package aim to provide users with a standardized approach to GIS (Longley et al (2011).

\section{QGIS versus ARCGIS}

The article aims to fulfill a comparison between two software packets:

- ArcGis Desktop (commercial)

- QuantumGis (free)

The goal is to compare and analyze both systems based on various geoanalysis tasks.

- Geo-referencing of aerial images

- Data capture (Digitizing)

- Spatial analysis (Raster and Vector analysis)

- Spatial Data Models,

- Raster models, Continuous Fields;

- Vector-to-Raster Conversion;

- Spatial Interpolation

- Map Algebra, Boolean Operators, Operators (Local/Focal/Zonal/Global),

- Point pattern analysis

- Spatial autocorrelation

- Local statistics

- Deterministic Interpolation Methods/ Geo statistical Interpolation Methods

- Spatial processes

- Spatial interpolation

- Trend surface and krigging

- Navigation and Routing (Network analysis)

\subsection{QGIS}

QGIS is a user friendly Open Source Geographic Information System (GIS) licensed under the GNU General Public License. QGIS is an official project of the Open Source Geospatial Foundation (OSGeo). It runs on Linux, Unix, Mac OSX, Windows and Android and supports numerous vector, raster, and database formats and functionalities. (http://www.qgis.org/en/site/about/index.html)

Some advantages:

- QGIS is free. ArcGis is commercial.

- QGIS can be installed on various operating systems, such as Windows, Mac OS X, Linux (Ubuntu), and Unix.

- With respect to DATA TRANSLATION AND CONVERSION, particularly for the vector formats, it is prefered QGIS. QGIS allows you to input/output WellKnownText (WKT), which can be extremely useful.

- You can also connect directly to many database engines. QGIS allows you to connect directly to MySQL, PostGRESql/PostGis and others, so you can make simple edits right in your database.

- The power of Qgis increments with Pluggins, which might be called and integrated within Qgis environment. The integration of these modules offers a very complex geospatial analysis. We 
mention here plugins as: Sextante (mainly functions for geospatial analysis), Grass, Saga, Orfeo toolbox, Ftools, R, Gdal/Ogr and many others libraries.

For Example: if you have to do raster analysis, you can do this using the plugins Grass into Qgis, as welled to fulfill this raster analysis in ArcGis, it must be purcased not only ArcGis, but also Spatial Analyst Extension.

\subsection{Licensing}

Since Qgis is a software of FOSS type (free and open source software), there do not exist any problems with licenses. It might be installed in any kind of computers.

\subsection{Development}

Qgis gets developed mainly from voluntaries programmer. But also differents funds alocates from private foundations etc. All of these do help in development of various versions and the updating of its functionalities.

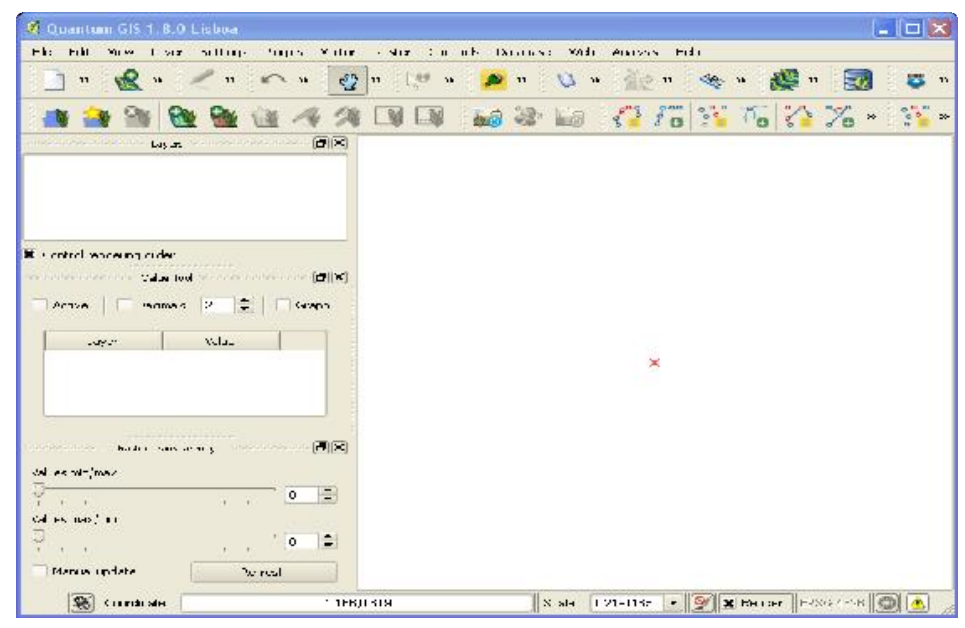

Figure.1 Qgis Interface (www.qgis.com)

\subsection{Support}

QGIS offers peer support via the gis.stackexchange.com site (http://www gis.stackexchange.com). Also notes that both user and technical support for QGIS are available via OSGeo.org's mailing lists (http://www.OSGeo.org/). The Support of Qgis increases daily and from different governments in the framework of their antimonopolistic policies.

\section{ARCGIS}

Esri's ArcGIS is a geographic information system (GIS) for working with maps and geographic information. It is used for: creating and using maps; compiling geographic data; analyzing mapped information; sharing and discovering geographic information; using maps and geographic information in a range of applications; and managing geographic information in a database (www.arcgis.com). 
It is important to emphasize that Arcgis software is being more complete toward functionalities and it is more powerful than Qgis. But being based simply in fulfilling of aims at our teaching courses, and what is more important the limited financial possibilities, we suggest the implementation of Qgis software at Gis labs.

- $\quad$ Arcgis is a very complete software, with various applications in industry, government etc.

\subsection{Licensing}

Arcgis software might be used on basis the licenses for seats.

\subsection{Development}

- Arcgis gets developed completely from ESRI Company (worldwide leader in GIS technologies) (www.arcgis.com).

- The functionalities of ArcGIS might be extended through modules so called extensions.

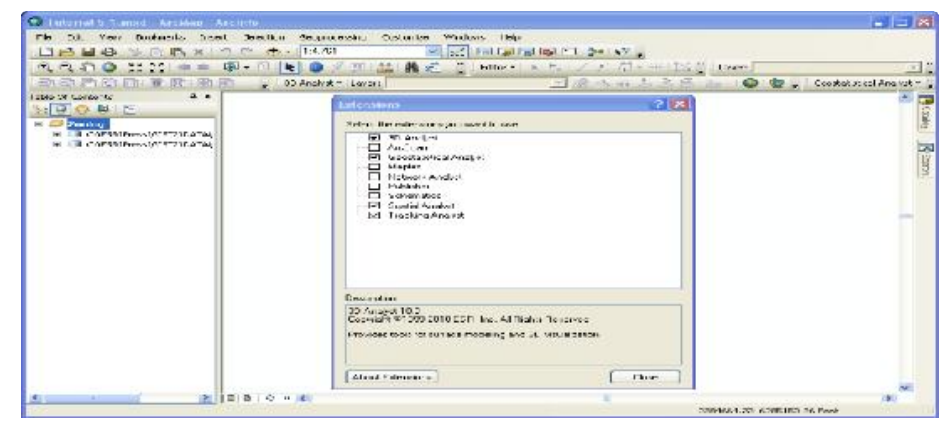

Figure 2 ArcGis Interface (www.arcgis.com)

\subsection{Support}

Esri has a well established knowledge base, peer support forum, and technical support system for its ArcGIS product.

\section{Discussions}

Currently, however, open source software are not mature enough to completely replace proprietary systems. This might be emphasized in the case of Qgis versus ArcGis.

Stability is often a crucial drawback to using Open Source software. This is because of inconsistent coding quality, often in plugins, and because of modular development itself, which demands tight coupling that is not always implemented. Stability should eventually be improved as part of the development process. Any comparisons on various functionalities of Qgis and Arcgis might be found in the Internet e.g. (http://www.donmeltz.com/arcgisqgis-faceoff/)

Though the intended audience of QGIS and ArcGIS is not explicitly different, the open source process has QGIS geared more towards scientists and programmers. For the scientist or academic, high configuration overhead is sometimes desirable, giving more control over the operation of the package, while precise language is sometimes helpful, belying the actual underlying math being 
performed by the tool. However, these factors prove a severe barrier to beginners or less technical users, who don't benefit from the superior programability inherent in the Open Source model.

\section{Conclusions}

We believe that the current state of Qgis is suited for advanced GIS courses only. That is, courses where the task is not to understand the basics, but to enhance the applied skills of the students. In our opinion, courses on an introductory level are better off with established, stable and well documented GIS software products. This ensures a motivating teaching environment, such that students can focus on experimenting with data and functionalities, rather than having to struggle with workarounds and ambiguous interfaces. We believe, however, that the two compared GIS can, under certain constraints, be utilized for teaching. Comparing to ArcGIS, QGIS can be installed on various operating systems, such as Windows, Mac OS X, Linux (Ubuntu), and Unix, while ArcGIS only has Windows version.In the teaching of geospatial concepts, most of the curriculum uses free and open-source software (FOSS) to achieve this goal. Open-source GIS software allows students to experience such systems without the need to acquire costly licenses.

\section{References}

1. Michael J de Smith, Michael F Goodchild, Paul A Longley .(2007). Geospatial

2. Analysis - A Comprehensive Guide to Principles, Techniques, and Software Tools Publisher: Troubador Publishing Ltd; 2 edition ISBN-10: 1906221987, ISBN-13: 978-1906221980.

3. Longley, Paul A., Goodchild, Michael F., Maguire, David J., Rhind, David, W.,( 2011) Geographic Information Systems \& Science. Wiley

4. Mawson, S. (ed.) (2001). Easy asignment writing. Doubleday Books, Sydney.

5. Moore, John W.,(1998) Education versus Training. University of Wisconsin at Madison, Madison, WI. Journal of Chemical Education.

6. http://www.spatialanalysisonline.com/output/.[accessed 1.10.2014].

7. http://www.qgis.org/en/site/about/index.html/.[accessed 1.10.2014]

8. http://www gis.stackexchange.com/.[accessed 1.10.2014]

9. http://www.OSGeo.org/.[accessed 1.10.2014]

10. http://www.donmeltz.com/arcgisqgis-faceoff/.[accessed 1.10.2014] 